\title{
Comunicação
}

[Communication]

\section{Avaliação do fluido peritoneal de asininos}

\author{
[Evaluation of peritoneal fluid from asinines]
}

\author{
M.F.C. Louro $^{1}$, R.V.C. Dias $^{2}$, B. Soto-Blanco ${ }^{2 *}$ \\ ${ }^{1}$ Prefeitura Municipal de Cariús, CE \\ ${ }^{2}$ Departamento de Medicina Veterinária - ESAM \\ Caixa Postal 147 \\ 59625-900 - Mossoró, RN.
}

Os asininos são animais muito resistentes, que podem sobreviver por vários dias sob condições adversas, tais como alimentação escassa e forragem muito fibrosa. Como todo eqüídeo, o jumento também é acometido por doenças relacionadas à síndrome do abdômen agudo, pois esses animais possuem baixo limiar para dor, sendo freqüentes os distúrbios digestivos, resultando em distensão intestinal (Smith, 1993). Desse modo, as doenças abdominais são importantes problemas clínicos em eqüídeos, e as lesões intra-abdominais resultam em alterações citológicas e bioquímicas no fluido peritoneal (Thomassian, 1995).

O exame do fluido peritoneal pode fornecer várias informações úteis para o estabelecimento do diagnóstico, a indicação da terapêutica clínica ou cirúrgica e o prognóstico (Tulleners, 1983; Thomassian, 1995), principalmente em situações nas quais outros exames podem se mostrar inconclusivos quando considerados isoladamente (Macoris, 1995). O líquido peritoneal também reflete o estado patofisiológico das superfícies mesoteliais visceral e parietal do peritôneo (Malark et al., 1992).

Informações referentes ao fluido peritoneal de eqüinos já estão bem descritas em estudos realizados no Brasil e no exterior, mas faltam estudos sobre asininos. Assim, neste trabalho realizou-se a avaliação do fluido peritoneal de jumentos com o intuito de auxiliar no estabelecimento de parâmetros de normalidade, relacionar os parâmetros avaliados dos asininos com os de eqüinos disponíveis na literatura e avaliar o intervalo de tempo entre as coletas do fluido, fornecendo subsídios para pesquisas futuras.

Foram utilizadas seis jumentas (Equus asininus), adultas, não gestantes, sem raça definida (SRD), examinadas clinicamente e vermifugadas, todas mantidas em piquete. A alimentação consistia em silagem desidratada e capim fornecido, assim como a água, ad libitum. A cada dois dias, os animais foram examinados clinicamente até quatro dias após o término das coletas.

As coletas foram efetuadas no período da manhã, com a finalidade de evitar estresse nos animais. Os animais foram contidos em posição quadrupedal, e o operador, usando luvas de procedimento, obteve o líquido peritoneal por punção na porção mais baixa do abdômen, entre o processo xifóide e o umbigo, área previamente tricotomizada e preparada assepticamente. Uma agulha de calibre $40 \times 12$ foi introduzida lentamente na pele, em inclinação próxima a $90^{\circ}$, na região da linha média, até que o fluido fosse obtido. Se houvesse contaminação com conteúdo digestivo, a agulha era retirada e a paracentese era realizada em outro local, deslocando a punção em sentido caudal ou cranial. 
O líquido foi coletado a cada 72 horas, durante um período de 21 dias. Foram realizadas oito coletas em cada animal, totalizando 48 amostras. As amostras foram coletadas em tubos de ensaio contendo solução de EDTA a 10\%, homogeneizadas em seguida, e levadas imediatamente para as análises. No laboratório, o exame do líquido peritoneal consistiu no exame macroscópico, na contagem celular total, na análise citológica diferencial e na determinação de proteínas totais.

$\mathrm{Na}$ avaliação macroscópica, após a homogeneização das amostras, foram observados a coloração e o grau de turbidez. A coloração foi classificada em amarelo-palha, laranja, vermelha e outras (cinza, marrom, verde), e o grau de turbidez em límpido, ligeiramente turvo e turvo.

As contagens celulares foram realizadas com dois diluidores diferentes, sendo uma para todas as células (incluindo eritrócitos) e outra para leucócitos e células mesoteliais. Para as duas contagens, foi utilizado o mesmo procedimento: diluição de $10 \mu \mathrm{l}$ da amostra homogeneizada na proporção de 1:100; os diluentes utilizados foram o soro fisiológico (para a contagem de todas as células) e o líquido de Thoma (para contagem de leucócitos e células mesoteliais, uma vez que os eritrócitos são rompidos). As contagens foram realizadas em câmara de Neubauer.

Para a análise citológica diferencial, parte da amostra foi centrifugada a $1500 \mathrm{rpm}$ por cinco minutos. Foram realizados esfregaços com o sedimento, corados pelo método Panótico ${ }^{1}$. A contagem diferencial foi realizada para um total de 100 leucócitos e células mesoteliais em microscópio óptico comum, em objetiva de 100x. A determinação da concentração de proteínas totais, no sobrenadante de amostras centrifugadas, foi realizada pelo método do biureto $^{2}$.

Em cada coleta, foram estimados as médias e os respectivos desvios-padrão para os números de hemácias, células mesoteliais, leucócitos totais, neutrófilos, linfócitos, macrófagos e eosinófilos e para a concentração de proteínas totais. Para os dados não paramétricos (coloração e turbidez),

\footnotetext{
${ }^{1}$ Instant-Prov, NewProv ${ }^{\circledR}$ - Pinhal, Brasil)

${ }^{2}$ Doles ${ }^{\circledR}$ - Goiânia, Brasil
}

foi feita uma distribuição de freqüências para cada tempo de avaliação.

Nas avaliações clínicas, as mucosas variaram de rósea a rósea pálida, o tempo de perfusão capilar sempre se manteve em torno de 2 seg, a temperatura retal variou de 37,4 a $38,3^{\circ} \mathrm{C}$ e a freqüência respiratória entre 36 e $42 \mathrm{bpm}$.

Nas abdominocenteses realizadas, a coleta foi fácil, geralmente com $o$ fluido peritoneal extravasando facilmente pela agulha, mas em algumas coletas, o líquido demorou um pouco a extravasar. Outra ocorrência foi a contaminação das amostras com sangue durante a coleta, mesmo em animais que não se movimentaram, devido a perfurações em vasos epiteliais periféricos das alças intestinais ou da parede abdominal (Coffman, 1980; Malark et al., 1992).

Em duas coletas, houve a enterocentese, diagnosticada pelo fato de o líquido obtido ser esverdeado (White, 1990), mas isso não trouxe complicações para o trabalho, pois a outra agulha foi introduzida caudalmente, com sucesso. Tampouco houve complicações para o animal, já que os achados clínicos não apresentaram indicativos de anormalidade. A penetração de uma agulha em um segmento sadio não distendido de uma alça intestinal é, provavelmente, livre de conseqüências graves para o animal, pois um orifício pequeno fecha-se rapidamente (Tulleners, 1983). As conseqüências da perfuração de uma alça distendida por acúmulo de gases ainda não estão bem elucidadas.

A análise macroscópica das amostras (Tab. 1) revelou coloração variando entre amarelo-palha, laranja (xantocromia) e vermelha. O amarelopalha é considerado normal para eqüinos (Thomassian, 1990; Macoris, 1995; Neves et al., 2000; Radostits et al., 1988). A contaminação sangüínea provavelmente foi a responsável pelas colorações vermelha e xantocrômica observadas, sendo a primeira relacionada à contaminação mais recente que a segunda. A turbidez variou de ligeiramente turva a turva, o que difere dos eqüinos, nos quais o aspecto ligeiramente turvo é caracterizado como normal, e o turvo foge da normalidade (Thomassian, 1990; Macoris, 1995; Neves et al., 2000). O grau de turbidez está relacionado à quantidade de proteínas e à 
celularidade (White, 1990; Macoris, 1995; Faria, 1998).

Os resultados encontrados para a contagem celular e concentração de proteína total são apresentados na Tab. 2, e os da análise citológica na Tab. 3. Os níveis de proteínas totais (Tab. 4) foram semelhantes aos encontrados em eqüinos (Macoris, 1995; Neves et al., 2000), e o número de leucócitos mais altos (Coffman, 1980; Neves et al., 2000).

Tabela 1. Variações percentuais da cor e turbidez do fluido peritoneal de asininos em relação ao dia da coleta

\begin{tabular}{|c|c|c|c|c|c|c|}
\hline \multirow[b]{2}{*}{ Dia da coleta } & \multicolumn{3}{|c|}{ Coloração } & \multicolumn{3}{|c|}{ Turbidez } \\
\hline & Amarelo-palha & Laranja & Vermelha & Límpido & Ligeiramente turvo & Turvo \\
\hline 0 & 100 & 0 & 0 & 0 & 50 & 50 \\
\hline 3 & 100 & 0 & 0 & 0 & 33,3 & 66,7 \\
\hline 6 & 16,7 & 50 & 33,3 & 0 & 16,7 & 83,3 \\
\hline 9 & 16,7 & 66,7 & 16,7 & 0 & 0 & 100 \\
\hline 12 & 66,7 & 33,3 & 0 & 0 & 0 & 100 \\
\hline 15 & 33,3 & 66,7 & 0 & 0 & 33,3 & 66,7 \\
\hline 18 & 66,7 & 0 & 33,3 & 0 & 50 & 50 \\
\hline 21 & 50 & 33,3 & 16,7 & 0 & 16,7 & 83,3 \\
\hline Média geral & 56,25 & 31,25 & 12,5 & 0 & 25,0 & 75,0 \\
\hline
\end{tabular}

Tabela 2. Médias e respectivos desvios-padrão de hemácias, leucócitos, células mesoteliais e concentração de proteínas totais no fluido peritoneal de asininos em relação ao dia da coleta

\begin{tabular}{ccccc}
\hline Dia da coleta & $\begin{array}{c}\text { Hemácias } \\
\left(\mathrm{x} 10^{3} / \mathrm{mm}^{3}\right)\end{array}$ & $\begin{array}{c}\text { Leucócitos } \\
\left(\mathrm{x} 10^{3} / \mathrm{mm}^{3}\right)\end{array}$ & $\begin{array}{c}\text { Células mesoteliais } \\
\left(\mathrm{x} 10^{3} / \mathrm{mm}^{3}\right)\end{array}$ & $\begin{array}{c}\text { Proteínas totais } \\
(\mathrm{g} / \mathrm{dl})\end{array}$ \\
\hline 0 & $7,08 \pm 1,88$ & $29,8 \pm 11,0$ & $6,65 \pm 2,18$ & $2,64 \pm 0,25$ \\
3 & $13,7 \pm 3,95$ & $18,48 \pm 3,66$ & $3,64 \pm 0,95$ & $2,00 \pm 0,12$ \\
6 & $41,3 \pm 14,2$ & $19,6 \pm 3,15$ & $4,69 \pm 1,02$ & $1,99 \pm 0,13$ \\
9 & $36,1 \pm 15,5$ & $15,1 \pm 4,53$ & $3,73 \pm 1,25$ & $2,09 \pm 0,15$ \\
12 & $19,8 \pm 5,14$ & $10,9 \pm 3,27$ & $2,79 \pm 0,76$ & $1,74 \pm 0,13$ \\
15 & $19,3 \pm 4,51$ & $8,83 \pm 2,10$ & $2,67 \pm 0,47$ & $1,76 \pm 0,18$ \\
18 & $28,7 \pm 10,9$ & $11,6 \pm 2,91$ & $3,09 \pm 0,80$ & $1,67 \pm 0,19$ \\
21 & $31,5 \pm 11,2$ & $11,9 \pm 3,76$ & $3,51 \pm 1,05$ & $1,91 \pm 0,31$ \\
Média Geral & $24,7 \pm 11,7$ & $15,8 \pm 6,79$ & $3,85 \pm 1,30$ & $1,97 \pm 0,31$ \\
CV (\%) & 47,2 & 43,0 & 33,8 & 15,5 \\
\hline
\end{tabular}

$\mathrm{CV}=$ coeficiente de variação

Tabela 3. Médias e respectivos desvios-padrão dos valores absolutos ( $\left.\times 10^{3} / \mathrm{mm}^{3}\right)$ e relativos $(\%)$ de leucócitos no fluido peritoneal de asininos em relação ao dia da coleta

\begin{tabular}{|c|c|c|c|c|c|c|c|c|}
\hline \multirow[b]{2}{*}{ Dia da coleta } & \multicolumn{2}{|l|}{ Neutrófilos } & \multicolumn{2}{|c|}{ Linfócitos } & \multicolumn{2}{|c|}{ Macrófagos } & \multirow[b]{2}{*}{$\mathrm{x} 10^{3} / \mathrm{mm}^{3}$} & \multirow{2}{*}{$\begin{array}{c}\text { Eosinófilos } \\
\%\end{array}$} \\
\hline & $\mathrm{x} 10^{3} / \mathrm{mm}^{3}$ & $\%$ & $\mathrm{x} 10^{3} / \mathrm{mm}^{3}$ & $\%$ & $\mathrm{x} 10^{3} / \mathrm{mm}^{3}$ & $\%$ & & \\
\hline 0 & $19,4 \pm 7,25$ & $53,2 \pm 5,29$ & $2,44 \pm 0,93$ & $6,83 \pm 0,87$ & $2,30 \pm 1,04$ & $5,83 \pm 1,25$ & $5,62 \pm 3,26$ & $14,7 \pm 3,97$ \\
\hline 3 & $13,1 \pm 2,73$ & $59,0 \pm 5,51$ & $1,70 \pm 0,27$ & $8,33 \pm 1,17$ & $1,11 \pm 0,33$ & $4,67 \pm 0,61$ & $2,54 \pm 0,95$ & $11,8 \pm 3,12$ \\
\hline 6 & $14,4 \pm 2,45$ & $59,2 \pm 4,45$ & $1,78 \pm 0,31$ & $7,50 \pm 0,85$ & $0,74 \pm 0,22$ & $3,17 \pm 0,87$ & $2,75 \pm 0,81$ & $11,0 \pm 2,22$ \\
\hline 9 & $10,8 \pm 2,77$ & $59,8 \pm 3,26$ & $1,19 \pm 0,25$ & $7,00 \pm 0,93$ & $0,74 \pm 0,33$ & $3,50 \pm 0,50$ & $2,39 \pm 1,25$ & $10,2 \pm 2,10$ \\
\hline 12 & $7,56 \pm 2,19$ & $55,2 \pm 2,40$ & $1,08 \pm 0,19$ & $9,00 \pm 1,51$ & $0,77 \pm 0,21$ & $5,67 \pm 0,95$ & $1,51 \pm 0,80$ & $9,50 \pm 2,26$ \\
\hline 15 & $5,76 \pm 1,20$ & $50,7 \pm 1,31$ & $0,99 \pm 0,23$ & $8,50 \pm 0,62$ & $0,69 \pm 0,14$ & $6,33 \pm 1,17$ & $1,39 \pm 0,62$ & $9,83 \pm 2,17$ \\
\hline 18 & $8,07 \pm 1,66$ & $57,8 \pm 2,99$ & $1,03 \pm 0,33$ & $6,50 \pm 0,67$ & $0,67 \pm 0,26$ & $4,00 \pm 0,58$ & $1,81 \pm 0,82$ & $9,83 \pm 3,42$ \\
\hline 21 & $8,18 \pm 2,34$ & $54,3 \pm 3,37$ & $1,11 \pm 0,34$ & $7,33 \pm 0,61$ & $0,81 \pm 0,27$ & $5,17 \pm 0,48$ & $1,86 \pm 1,04$ & $9,50 \pm 3,01$ \\
\hline Média geral & $10,9 \pm 4,51$ & $56,2 \pm 3,31$ & $1,41 \pm 0,51$ & $7,63 \pm 0,89$ & $0,98 \pm 0,55$ & $4,79 \pm 1,15$ & $2,48 \pm 1,36$ & $10,8 \pm 1,76$ \\
\hline $\mathrm{CV}(\%)$ & 41,3 & 5,90 & 36,3 & 11,7 & 56,5 & 24,1 & 54,7 & 16,3 \\
\hline
\end{tabular}

$\mathrm{CV}=$ coeficiente de variação 
Tabela 4. Valores obtidos para o fluido peritoneal de asininos e os descritos na literatura para eqüinos

\begin{tabular}{|c|c|c|}
\hline Parâmetro & Asininos & Eqüinos * \\
\hline Coloração & $\begin{array}{c}\text { Amarelo palha a } \\
\text { laranja }\end{array}$ & $\begin{array}{c}\text { Amarelo palha a } \\
\text { amarelo }\end{array}$ \\
\hline Turbidez & $\begin{array}{c}\text { Ligeiramente turvo } \\
\text { a turvo }\end{array}$ & Transparente \\
\hline Leucócitos & $\begin{array}{c}15,8 \pm 6,79 \times \\
10^{3} / \mathrm{mm}^{3}\end{array}$ & $4,33 \times 10^{3} / \mathrm{mm}^{3}$ \\
\hline Hemácias & $\begin{array}{c}24,7 \pm 11,7 \times \\
10^{3} / \mathrm{mm}^{3}\end{array}$ & $4-6 \times 10^{3} / \mathrm{mm}^{3}$ \\
\hline $\begin{array}{l}\text { Proteínas } \\
\text { totais }\end{array}$ & $1,97 \pm 0,31 \mathrm{~g} / \mathrm{dl}$ & $1,97 \pm 0,31 \mathrm{~g} / \mathrm{dl}$ \\
\hline
\end{tabular}

* Segundo Thomassian (1995)

Relacionando a coloração, o grau de turbidez e os achados microscópicos, diversas coletas mostraram incidências semelhantes para contaminação sangüínea e turbidez, confirmando que há aumento da turbidez quando há contaminação sangüínea (White, 1990; Macoris, 1995). Nas coletas realizadas após três e 12 dias, o aumento da turbidez pode estar relacionado ao número de eritrócitos presentes na amostra, pois um pequeno número delas pode aumentar a turbidez, sem que ocorra o aparecimento avermelhado (Macoris, 1995).

$\mathrm{Na}$ análise citológica, o tipo celular prevalente nos jumentos foi o neutrófilo, semelhante ao observado em eqüinos (Parry e Brownlow, 1992). A prevalência dos demais leucócitos, em ordem decrescente, foi de eosinófilos, linfócitos e macrófagos, o que difere dos eqüinos, nos quais essa ordem muda para macrófagos, linfócitos e eosinófilos (Parry e Brownlow, 1992). A maior ocorrência de eosinófilos nos asininos pode ser devido à variação entre as espécies ou a uma infecção parasitária não detectada, apesar da vermifugação dos animais.

Palavras-chave: jumento, fluido peritoneal, líquido cavitário, efusão

\section{ABSTRACT}

The peritoneal fluid from six female health donkeys was evaluated. In each animal, it was carried out eight abdominocentesis with 40x12 needles, at 72-hour intervals. All animals presented clinical changes, and there was higher frequency of yellow-tinged fluid with turbidity aspect. Means, and respective standard deviations, for cytology and protein concentration were: erythrocytes, $24.7 \pm 11.7 \times 10^{3} / \mathrm{mm}^{3}$; leukocytes, $15.8 \pm 6.79 \times 10^{3} / \mathrm{mm}^{3}$; mesothelial cells, $3.85 \pm 1.30 \times 10^{3} / \mathrm{mm}^{3}$; neutrophils, $10.9 \pm 4.51 \times 10^{3} / \mathrm{mm}^{3}$; lymphocytes, $1.41 \pm 0.51 \times 10^{3} / \mathrm{mm}^{3}$; macrophages, $0.98 \pm 0.55 \times 10^{3} / \mathrm{mm}^{3}$; eosinophils, $2.48 \pm 1.36 \times 10^{3} / \mathrm{mm}^{3}$, and total proteins, $1.97 \pm 0.31 \mathrm{~g} / \mathrm{dl}$.

Keywords: donkey, peritoneal fluid, cavitary liquid, effusions

\section{REFERÊNCIAS BIBLIOGRÁFICAS}

COFFMAN, J.R. Peritoneal fluid. Vet. Med. Small Anim. Clin., v. 75, p.1285-1288, 1980

FARIA, E.P. Características bioquímicas e citológicas do líquido peritoneal de eqüinos submetidos a peritonite experimental. 1998. 138f. Dissertação (Mestrado) - Escola de Veterinária. Universidade Federal de Minas Gerais, Belo Horizonte.

MACORIS, D.G. Importância da avaliação do líquido peritoneal no diagnóstico e prognóstico da cólica. In: CICLO INTERNACIONAL DE CÓLICA EQÜINA, 2., 1995 , Jaboticabal. Anais... Jaboticabal, 1995. p.21-23.

MALARK, J.A.; PEUTON, L.C.; GALVIN, M.J. Effects of blood contamination on equine peritoneal fluid analysis. $J$. Am. Vet. Med. Assoc., v.201, p.1545-1548, 1992.

NEVES, M.M.; MARQUES Jr., A.P.; ALVES, G.E.S. et al. Valores referenciais da análise do líquido peritoneal de eqüinos sadios. Ciên. Rural, v.30, p.809-811, 2000.
PARRY, B.W.; BROWNLOW, M.A. Peritoneal fluid. In: COWELL, R.L.; TYLER, R.D. (Eds.). Cytology and hematology of the horse. Santa Bárbara: American Veterinary Publications, 1992. p.121-151.

RADOSTITS, O.M.; GAY, C.C.; BLOOD, D.C. et al. Doenças do sistema digestório - I. In: Clínica veterinária. 9.ed. Rio de Janeiro: Guanabara Koogan, 1988. p.150-234.

SMITH, B.P. Tratado de medicina interna de grandes animais. v.1. São Paulo: Manole, 1993. 900p.

THOMASSIAN, A. Enfermidades dos cavalos. 2.ed. São Paulo: Varela, 1990. 561p.

THOMASSIAN, A. Exame clínico do paciente eqüino com cólica. In: CICLO INTERNACIONAL DE CÓLICA EQUINA, 2., 1995, Jaboticabal. Anais... Jaboticabal, 1995. p.10-17.

TULLENERS, E.P. Complications of abdominocentesis in the horse. J. Am. Vet. Med. Assoc., v.182, p.232-234, 1983.

WHITE, N.A. The eqüine acute abdomen. Philadelphia: Lea \& Febiger, 1990. 434p. 